\title{
VULNERABILITY OF COASTAL STRUCTURES WITH FUSE ELEMENTS
}

Abanades, J., Campos, A. and Castillo, C. University of Castilla-La Mancha (Spain)

Javier.Abanades@alu.uclm.es, Alvaro.Campos@uclm.es, MariaCarmen.Castillo@uclm.es

Escuela de Ingenieros de Caminos
Canales y Puertos de Ciudad Real

Molina, R. Harbour Research Laboratory. C.P. Bueno, Technical University of Madrid (Spain)

rmolina@caminos.upm.es

Laboratorio de Puertos

\section{Introduction}

Vulnerability of coastal structures is very important especially in low-lying areas considering sea level rise and the increase in severity of other associated agents.

The vulnerability of a vertical breakwater is defined as the probability of attaining a level of damage under different classes of external actions. The damage can be related to reliability or operationality and the external action is defined with a global descriptor, usually, it will be the maximum significant wave height in a storm.

\section{Fuse element}

In May 2004, a storm event in Motril (Southern Spain) removed a long stretch of the parapet of the breakwater. Experts consider that the removal of the parapet prevented the collapse of the whole structure.
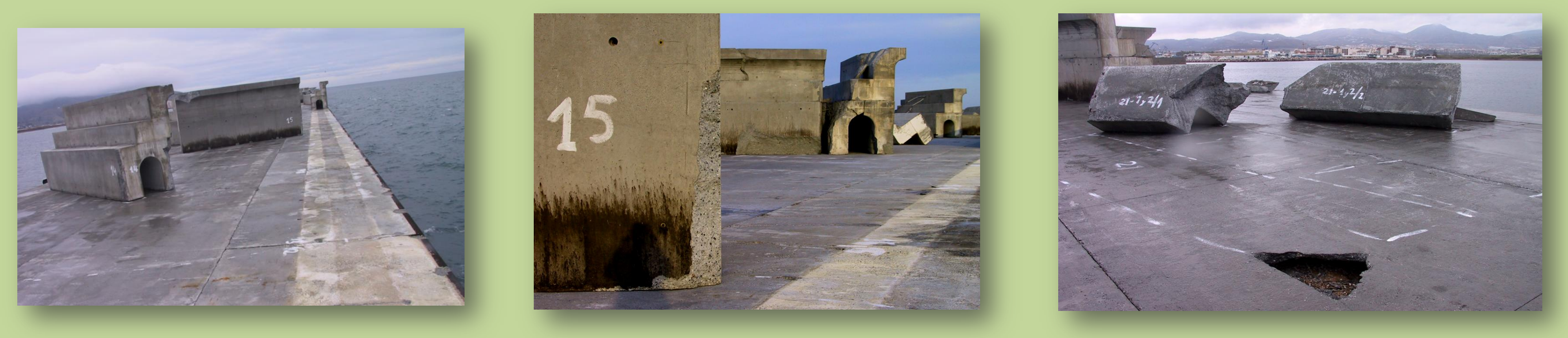

Figure 1: Damage generated in the vertical breakwater during the storm event in Motril

Campos et al. (2010) and Campos (2012) optimized the design of a breakwater with a fuse parapet concluding that the width of the caisson could be reduced with respect to the fixed parapet case due to the fact that the fuse element reduces the failure probability of the whole structure.

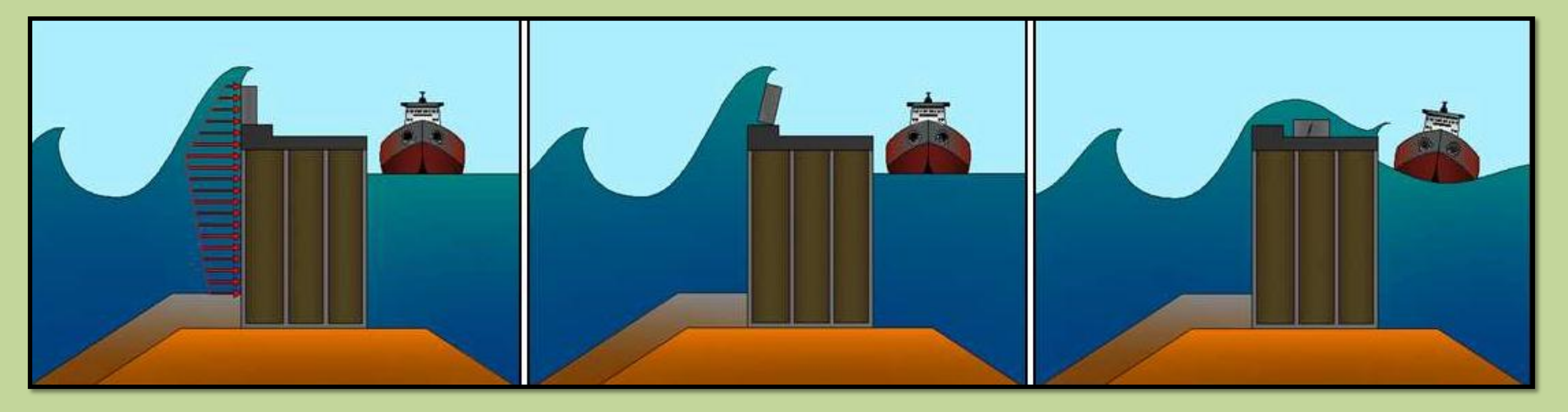

Figure 2: Fuse element (Campos 2012)

However, operationality can be severely affected by fuse fall and the associated overtopping increase so the vulnerability of the structure has been studied considering the activities at the leeward side of the breakwater.

\section{Methodology}

\section{Sections}

- Actual breakwater in Motril $(B=21 \mathrm{~m})$ with fixed parapet

- Actual breakwater in Motril $(B=21 \mathrm{~m})$ with fuse parapet

- Optimized breakwater ( $B=9.8 \mathrm{~m}$ ) with fuse element (Campos, 2012)

- Optimized section for fuse parapet applied to fixed parapet case $(B=9.8 \mathrm{~m})$

\section{Exploitation cases}

- Case 1: Solid bulks (actual use)

- Case 2: Passengers

- Case 3: No exploitation

\section{Failure modes}

\section{Caisson tilting}

1. Caisson tilting Caisson failure

2. Caisson sliding

3. Parapet/fuse element tilting $]$ Parapet / fuse

4. Parapet/fuse element sliding $\int$ element failure

5. Overtopping

6. Toe erosion

7. Berm erosion $\}$ Rock failure
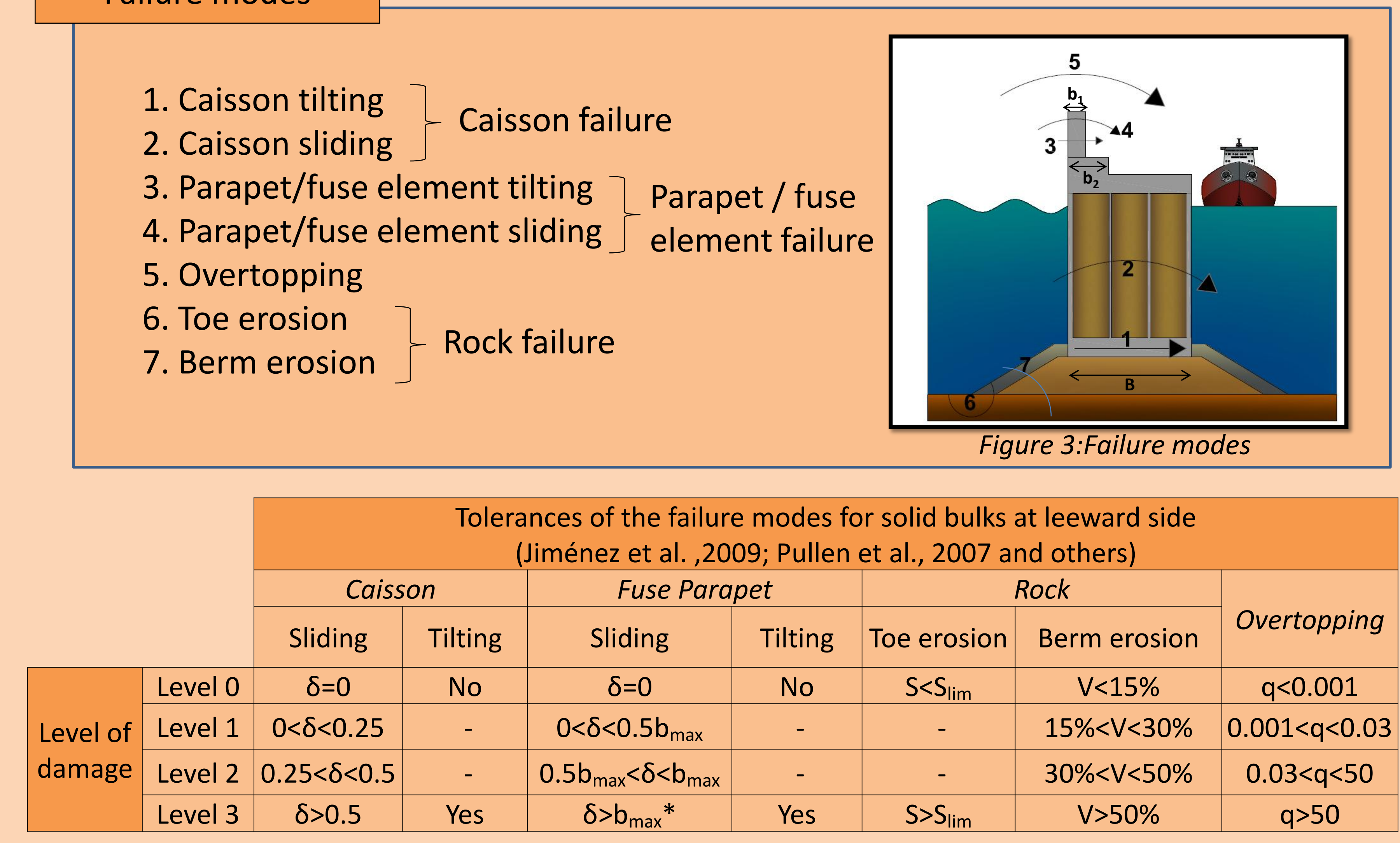

$\delta(m)$ is the displacement, $S(m)$ is the erosion depth and $S_{\text {lim }}(m)$ is the depth limit $V$ is the variation of the berm area and $q(1 / s / m)$ is the discharge

${ }^{*} b_{\text {max }}=b_{2}-0.5 b_{1}$ (see figure 3 )

Damage levels

- Level 0 : Operationa

- Level 1 : Brief operational stoppage due to a slight breakdown

- Level 2 : Long operational stoppage

- Level 3: Collapse, the structure doesn't serve its purpose.
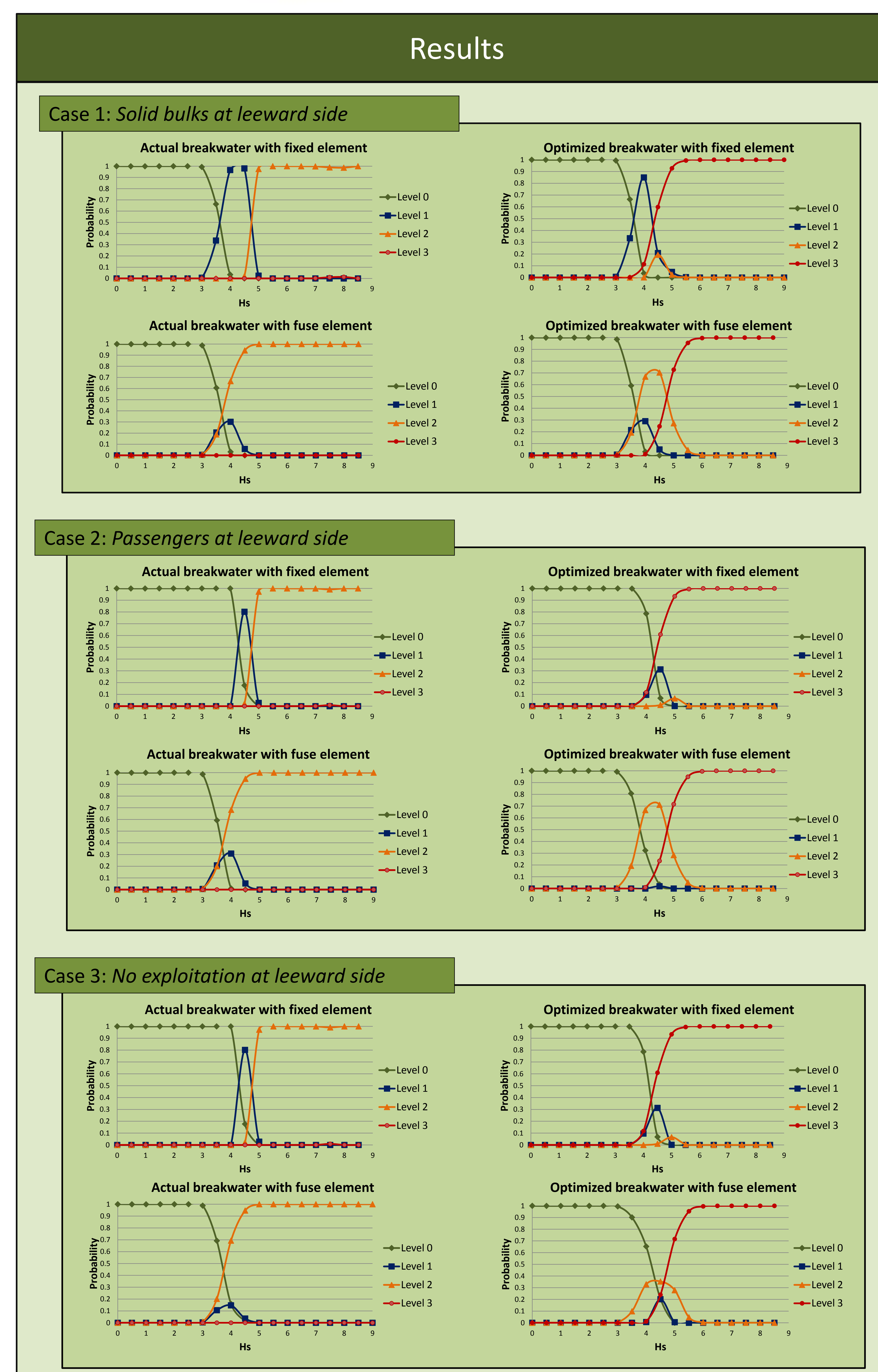

Conclusions

1. As expected, the comparison between actual and optimized breakwater shows an increase of the probability of collapse (level 3) for $\mathrm{H}_{\mathrm{s}}>4 \mathrm{~m}$, although these waves have a small probability of occurrence. The latter section was designed using probabilistic techniques.

2. On one hand, the comparison between sections with and without fuse element shows an increase on the probability of damage level 2 in the former because this level includes the simultaneous occurrence of fuse failure and, therefore, an increase in overtopping which exceeds the tolerance.

3. On the other hand, the fuse element reduces the probability of level 3 (collapse: caisson failure) for $\mathrm{H}_{\mathrm{s}}$ between 4 and $6 \mathrm{~m}$ for the optimized section.

4. The fuse element is shown to be more efficient when there are no activities on the lee of the breakwater.

\section{References}

Campos, A., Castillo, C. and Molina, R. (2010), Optimizing breakwater design considering the system of failure modes. Proc. International Conference on Coastal Engineering

Campos, A. (2012), Advances in the design of fuse breakwaters. Master Thesis.(In Spanish) Jiménez, M., Egozcue, J. and Corral, J. (2009), Vulnerability of vertical breakwater using Monte Carlo simulation (in Spanish)

Pullen, T., Allsop, W., Bruce, T., Kortenhaus, A., Schüttrumpf, H.,Van der Meer, J. W., (2007) EUROTOP. Wave Overtopping of Sea Defences and Related Structures: Assessment Manual.

\section{Acknowledgements}

The authors are indebted to the Spanish Ministry of Science and Innovation (project BIA2009-10483 and grant BES-2010-034048) and to the Spanish Ministry of Education for partial support. 